\title{
Article
}

\section{Pyrolysis of Rice Straw Using Radio-Frequency Plasma}

Wen-Kai Tu, Je-Lung Shie, Ching-Yuan Chang, Chiung-Fen Chang, Cheng-Fang

Lin, Sen-Yeu Yang, Jing-Tsung Kuo, Dai-Gee Shaw, and Duu-Jong Lee

Energy Fuels, 2008, 22 (1), 24-30 • DOI: 10.1021/ef7002848 • Publication Date (Web): 29 September 2007

Downloaded from http://pubs.acs.org on November 20, 2008

\section{More About This Article}

Additional resources and features associated with this article are available within the HTML version:

- $\quad$ Supporting Information

- Access to high resolution figures

- $\quad$ Links to articles and content related to this article

- Copyright permission to reproduce figures and/or text from this article

\section{View the Full Text HTML}




\title{
Pyrolysis of Rice Straw Using Radio-Frequency Plasma ${ }^{\dagger}$
}

\author{
Wen-Kai Tu, $\stackrel{\ddagger}{\ddagger}$ Je-Lung Shie, ${ }^{\S}$ Ching-Yuan Chang,,$\stackrel{\ddagger}{\ddagger}$ Chiung-Fen Chang, " Cheng-Fang Lin, \\ Sen-Yeu Yang, ${ }^{\perp}$ Jing-Tsung Kuo, ${ }^{\perp}$ Dai-Gee Shaw, ${ }^{\#}$ and Duu-Jong Lee ${ }^{\nabla}$ \\ Graduate Institute of Environmental Engineering, Nation Taiwan University, 71, Choushan Road, \\ Taipei 10617, Taiwan, Department of Environmental Engineering, National I-Lan University, No. 1, \\ Sec. 1, Shen-Lung Road, Ilan 26041, Taiwan, Department of Environmental Science and Engineering, \\ Tung-Hai University, No. 181, Sec. 3, Taichung Harbor Road, Taichung 40704, Taiwan, Deparentments of \\ Mechanical Engineering and Chemical Engineering, Nation Taiwan University, No. 1, Sec. 4, \\ Roosevelt Road, Taipei 10617, Taiwan, and Chung-Hua Institution for Economic Research,
} No. 75, Changsing Street, Taipei 10672, Taiwan

Received May 28, 2007. Revised Manuscript Received August 21, 2007

\begin{abstract}
In this study, a radio-frequency (RF) plasma thermolysis reactor was used for pyrolyzing the biomass waste of rice straw. The effects of some major system parameters on the performance of the pyrolysis of rice straw via RF plasma were studied and elucidated. Examining the characteristics of the RF plasma thermolysis reactor with the working gas nitrogen indicates that as the loading power $\left(P_{\mathrm{WL}}\right)$ increases from 137 to $591 \mathrm{~W}$, the plateau temperature $\left(T_{\mathrm{P}}\right)$ of plasma increases from 607 to $954 \mathrm{~K}$. The corresponding times of $t_{\mathrm{H}}$ to reach $T_{\mathrm{P}}$ (the corresponding $t_{\mathrm{H}}$ is denoted as $t_{\mathrm{HP}}$ ) at 607 and $954 \mathrm{~K}$ are about 5 and $2 \mathrm{~min}$, respectively. Thus, a higher $P_{\mathrm{WL}}$ gives a higher $T_{\mathrm{P}}$ with a shorter $t_{\mathrm{HP}}$. The times of $t_{\mathrm{H}}$ with $P_{\mathrm{WL}}$ of 308,363 , and $591 \mathrm{~W}$ to reach a setting temperature $\left(T_{\mathrm{S}}\right)$ (the corresponding $t_{\mathrm{H}}$ is denoted as $t_{\mathrm{HS}}$ ) at $783 \mathrm{~K}$ are about $5,1.5$, and $0.67 \mathrm{~min}$, respectively. Again, a higher $P_{\mathrm{WL}}$ needs a shorter $t_{\mathrm{HS}}$ to reach the same $T_{\mathrm{S}}$. No tar product is formed via pyrolysis using RF plasma, while about $1.5 \mathrm{wt} \%$ of tar is produced using traditional electric-thermal heating. Thus, the gaseous products obtained via the former method would contain more hydrocarbons (HCs) of low molecular weight than those via the latter method. This indicates that the ability of cracking HCs via the former is better than the latter, supporting the idea that the former can provide syngas with better quality.
\end{abstract}

\section{Introduction}

Bioenergy from biomass has the potential to provide a significant portion of the projected renewable energy provisions for the future. Among the available biomasses, rice straw is one of the favorable bioenergy sources because it is the residue from the end use of the biomass products. The reutilization of rice straw not only saves the cost of disposal but also produces valuable bioenergy, achieving the goal of resources recovery and reuse. Taiwan is located in the subtropics and has excellent farming technology, thus producing abundant biomasses. However, this also results in a significant amount of agriculture wastes to be treated, with the rice straw contributing the most. In Taiwan, rice is one of the principal foods. According to the statistics of in season agricultural products of Taiwan, the total cultivated area is 230000 ha. The rice straw generated after being reaped from rice is about 6 tons $\mathrm{ha}^{-1}$. Thus, the total annual generation of rice straw is about 1.4 million tons, including the first and second crops. Its common treatment is on-site burning for producing manure. However, the open burning is harmful to the air quality and environment. Among

\footnotetext{
$\dagger$ Presented at the International Conference on Bioenergy Outlook 2007, Singapore, April 26-27, 2007.

* Corresponding author. Tel.: +886-2-2363-8994. Fax: +886-2-23638994. E-mail address: cychang3@ntu.edu.tw.

$¥$ Graduate Institute of Environmental Engineering, Nation Taiwan University.

\& National I-Lan University.

" Tung-Hai University.

${ }^{\perp}$ Deparentment of Mechanical Engineering, Nation Taiwan University.

\# Chung-Hua Institution for Economic Research.

$\nabla$ Department of Chemical Engineering, Nation Taiwan University.
}

the available biomasses, rice straw waste is one of the favorable bioenergy sources because it is the residue from the end use of the rice. The reutilization of rice straw waste not only saves the cost of disposal but also produces valuable bioenergy, achieving the goal of resources recovery and reuse.

Two main disadvantages of the pyrolysis and gasification of biomass wastes for producing medium calorific value gases via the traditional thermolysis technology are the following: (1) the gas yield is very low, reducing the energy value of gas, and (2) the amount of tar in the gas is high, causing corroding problems in the gas-collecting equipment. ${ }^{1-3}$ Adding catalyst in the pyrolysis or gasification of biomass is helpful for the product quality. Atutxa et al. ${ }^{4}$ pointed out that adding HZSM-5 catalyst can produce more gas products in the pyrolysis of sawdust. Waldner and Vogel $^{5}$ found that joining Ni-catalyst in the gasification of sawdust can get higher yield in output syngas ( $0.33 \mathrm{~g} \mathrm{CH}_{4}$ per gram of wood). To increase the liquid yield, Gullu ${ }^{6}$ used $\mathrm{Na}_{2} \mathrm{CO}_{3}$ and $\mathrm{K}_{2} \mathrm{CO}_{3}$ as catalysts in the pyrolysis of hazelnut shell, tea waste, and yellow pine. The results indicated

(1) Caldeira, M. I. K.; Benford, G.; Criswell, D. R.; Green, C.; Herzog, H.; Jain, A. K.; Kheshgi, H. S.; Lackner, K. S.; Lewis, J. S.; Lightfoot, H. D.; Manheimer, W.; Mankins, J. C.; Mauel, M. E.; Perkins, L. J.; Schlesinger, M. E.; Volk, T.; Wigley, T. M. L. Science 2002, 298, 981987.

(2) Bridgwater, A. V. Chem. Eng. J. 2003, 91, 87-102.

(3) Chen, G.; Andries, J.; Luo, Z.; Spliethoff, H. Energy Convers. Manage. 2003, 44, 1875-1884.

(4) Atutxa, A.; Aguado, R.; Gayubo, A. G.; Olazar, M.; Bilbao, J. Energy Fuels 2005, 19, 765-774.

(5) Waldner, M. H.; Vogel, F. Ind. Eng. Chem. Res. 2005, 44, 45434551.

(6) Gullu, D. Energy Sources 2003, 25, 753-765. 
that adding $\mathrm{Na}_{2} \mathrm{CO}_{3}$ is better than $\mathrm{K}_{2} \mathrm{CO}_{3}$ to give more liquid products. The humidity is also an enhancing factor. Adding steam can raise the liquid products in the pyrolysis of sawdust. ${ }^{7}$ The two disadvantages of the traditional thermolysis of biomass can be overcome by adding catalysts. However, the improvement of product quality for practical use is still not enough.

In order to overcome the disadvantages of thermolysis using traditional heating methods, a radio-frequency (RF) plasma heating method, which is also called the capacitive dielectric heating method, may be one of the alternative choices. The RF plasma heating method employs the alternating current with high frequency and voltage to build up an electromagnetic field producing plasma to induce the target material resulting in the vigorous colliding, rubbing, and, thus, self-heating. The RF plasma thermolysis reactor used in this study can be operated with changes of output voltage, pressure, energy density, and gas temperature. It can give better quality products under high frequency $\left(10^{5}-10^{7} \mathrm{~Hz}\right.$, e.g., at $\left.13.56 \mathrm{MHz}\right)$, high output power (as high as $2000 \mathrm{~W}$ ), and low pressure $\left(10^{3}-10^{6} \mathrm{~Pa}\right)$. As the material is heated, pyrolysis occurs. The heating method using RF has many advantages such as a high heating rate (HR), short heating time $\left(t_{\mathrm{H}}\right)$, low heat loss, and low residual tar. The notations $t_{\mathrm{HP}}$ and $t_{\mathrm{HS}}$ denote the values of $t_{\mathrm{H}}$ to reach $T_{\mathrm{P}}$ and $T_{\mathrm{S}}$ (the setting temperature), respectively. Hence, this novel method can overcome the problems encountered in the traditional pyrolysis of biomass. ${ }^{2,3,8-10}$

A low tar content in the product obtained from RF plasma thermolysis can be achieved because high energy species, such as electrons, ions, atoms, and free radicals, produced from RF plasma can enhance the decomposition of tar. ${ }^{11}$ Tang and Huang ${ }^{11}$ used RF plasma pyrolysis to treat the biomass of sawdust at various operating pressures (3000-8000 Pa) and input powers (1600-2000 W). On average, the gas yield can reach $66 \mathrm{wt} \%$ of the biomass feed at an input power of $1800 \mathrm{~W}$ and an operating pressure of $5000 \mathrm{~Pa}$. The total content of $\mathrm{CO}$ and $\mathrm{H}_{2}$ in the gas product reached $76 \mathrm{vol} \%$ on a nitrogen-free basis, which can be used as syngas components. The solid product has a large Brunauer-Emmett-Teller (BET) surface area of 278 $\mathrm{m}^{2} \mathrm{~g}^{-1}$ and a large pore volume of $0.15 \mathrm{~cm}^{3} \mathrm{~g}^{-1}$. The applications of plasma techniques used are widespread in treating hazardous wastes and flare gas, ${ }^{12}$ such as polypropylene,${ }^{13}$ municipal solid waste, ${ }^{14}$ electrosludge,${ }^{15}$ polychlorinated biphenyls (PCBs),${ }^{16}$ carbonaceous waste, ${ }^{17}$ waste tires, ${ }^{18}$ benzene, ${ }^{19}$ 1,2-dichloroethane (DCE) ${ }^{20}$ and halogenated hydrocar-

(7) Demirbas, A. Energy Sources 2005, 27, 823-830.

(8) Zhao, Z. L.; Huang, H. T.; Wu, C. Z.; Li, H. B.; Chen, Y. Chem. Eng. Technol. 2001, 24, 197-199.

(9) Merida, W.; Maness, P. C.; Brown, R. C.; Levin, D. B. Int. J. Hydrogen Energy 2004, 29, 283-290.

(10) Yaman, S. Energy Convers. Manage. 2004, 45, 651-671.

(11) Tang, L.; Huang, H. Energy Fuels 2005, 19, 1174-1178.

(12) Mollah, M. Y. A.; Schennach, R.; Patscheider, J.; Promreuk, S.; Cocke, D. L. J. Hazard. Mater. 2000, 79, 301-320.

(13) Guddeti, R. R.; Knight, R.; Grossmann, E. D. Plasma Chem. Plasma Process. 2000, 20, 37-64.

(14) Katou, K.; Asou, T.; Kurauchi, Y.; Sameshima, R. Thin Solid Films 2001, 386 (2), 183-188.

(15) Ramachandran, K.; Kikukawa, N. IEEE Trans. Plasma Sci. 2002, 30, 310-317.

(16) Kim, S. W.; Park, H. S.; Kim, H. J. Vacuum 2003, 70, 59-66.

(17) Nishikawa, H.; Ibe, M.; Tanaka, M.; Ushio, M.; Takemoto, T.; Tanaka, K.; Tanahashi, N.; Ito, T. Vacuum 2004, 73, 589-593.

(18) Tang, L.; Huang, H. J. Anal. Appl. Pyrolysis 2004, 72, 35-40.

(19) Shih, S. I.; Lin, T. C.; Shih, M. L. J. Hazard. Mater. 2004, 116, 239-248.

(20) Li, C. T.; Yang, R. B.; Shih, M. L.; Chen, C. Y.; Hsieh, L. T. J. Chem. Technol. Biotechnol. 2003, 78, 817-823. bons. ${ }^{21}$ In other applications, the RF plasma technique can be applied to the (1) manufacture of $\mathrm{SiO}_{2}$ nanofiber, ${ }^{22}$ nanocrystalline $\mathrm{ZnO}$ film, ${ }^{23}$ a $\mathrm{CeO}_{2}$-buffer layer, ${ }^{24}$ nanotubes, ${ }^{25}$ and fullerenes, ${ }^{26}$ (2) reduction of $\mathrm{SO}_{2}$ to element $\mathrm{S}$ (with $\mathrm{CH}_{4}$ as the reductant), ${ }^{27}$ (3) transformation of $\mathrm{CH}_{4}$ into syngas, ${ }^{28}$ and (4) generation of $\mathrm{H}_{2} \cdot{ }^{29}$ The thermal plasma pyrolysis of biomass for the production of energy and chemicals has seldom been studied even in laboratory investigations because of technical difficulties or applied for economic reasons. ${ }^{11}$ Today, one of the main factors that restricts the use of plasma-based methods is the cost of electrical energy. The crucial element is the operation and maintenance cost of the plasma generator and reactor. The ways to increase the efficiency of the process are also very important. In order to overcome parts of this problem, the need for electric energy for plasma technology may be supplied partly from the power generated via the use of the product of syngas. Tendler et al. ${ }^{31}$ addressed the fact that the energies stored in syngas are all higher than the energy consumption from the operation of plasma technology (a plasma torch). On the other hand, the investment costs of plants of plasma torches are typically 30-50\% lower than those of incinerators of the same capacity. ${ }^{30}$ Another effect of the operation cost for a plasma torch application is the cost of feedstock. Therefore, the best choice of feedstock is waste from biomass or waste organic materials.

\section{Experimental Section}

The schematic diagram of the RF plasma thermolysis system is shown in Figure 1. The RF plasma reactor consists of a quartz tube with an outer diameter of $50 \mathrm{~mm}$, a wall thickness of $2 \mathrm{~mm}$, and a length of $500 \mathrm{~mm}$. The electrodes are two pieces of copper arcs with a length of $320 \mathrm{~mm}$, which are fixed and covered around the outside of the quartz tube with a gap between two electrodes. The length of the RF plasma producing zone is about $320 \mathrm{~mm}$. The working gas is chosen as $\mathrm{N}_{2}$ with a purity of $99.99 \%$. Its flow rate $(Q)$ of working gas through the drying tube is controlled via a mass flow controller (Brooks, 5850E, USA). In all experiments, $Q$ is kept at

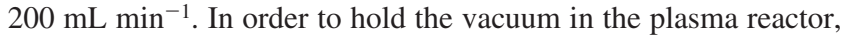
the sample is fed by a continuous feeding apparatus with two valves open and closed exchanged. The cold trap with a temperature of $298 \mathrm{~K}$ and a volume of $3 \mathrm{~L}$ is installed after the RF plasma thermolysis reactor to collect the liquid products. In order to maintain a suitable degree of vacuum in the plasma reactor, the switch valves and the vacuum meter (Terranova, model 906A) are installed. Three digital thermometers (TFC 305A, type K) are used to detect the temperatures of the RF plasma reactor and the inlet and outlet of the cold trap. The RF plasma power supply

(21) Watanabe, T.; Shimbara, S. High Temp. Mater. Process. 2003, 7, $455-474$.

(22) Zhang, G.; Kataphinan, W.; Teye-Mensah, R.; Katta, P.; Khatri, L.; Evans, E. A.; Chase, G. G.; Ramsier, R. D.; Reneker, D. H. Mater. Sci. Eng.: B 2005, 116, 353-358.

(23) Lee, J.; Gao, W.; Li, Z.; Hodgson, M.; Metson, J.; Gong, H.; Pal, U. Appl. Phys. A: Mater. Sci. Process. 2005, 80, 1641-1646.

(24) Sohma, M.; Yamaguchi, I.; Tsukada, K.; Kondo, W.; Kamiya, K.; Mizuta, S.; Manabe, T.; Kumagai, T. IEEE Trans. Appl. Superconductivity 2005, 15, 2699-2702.

(25) Lee, K. Y.; Ikuno, T.; Tsuji, K.; Ohkura, S.; Honda, S.; Katayama, M.; Oura, K.; Hirao, T. J. Vac. Sci. Technol. B 2003, 21, 1437-1441.

(26) Jenkins, G. M.; Holland, L. R.; Maleki, H.; Fisher, L. Carbon 1998, $36,1725-1727$.

(27) Tsai, C. H.; Lee, W. J.; Shih, M. L.; Chen, C. Y.; Tsai, P. J. AICHE J. 2004, 50, 524-529.

(28) Tsai, C. H.; Hsieh, T. H. Ind. Eng. Chem. Res. 2004, 43, 40434047.

(29) Li, H. Q.; Zou, J. J.; Liu, C. J. Prog. Chem. 2005, 17, 69-77.

(30) Shie, J. L.; Chang, C. Y.; Lin, J. P.; Lee, D. J.; Wu, C. H. J. Chin. Inst. Environ. Eng. 2001, 11, 307-316.

(31) Tendler, M.; Rutberg, P.; van Oost, G. Plasma Phys. Control. Fusion 2005, 47, A219-A230. 


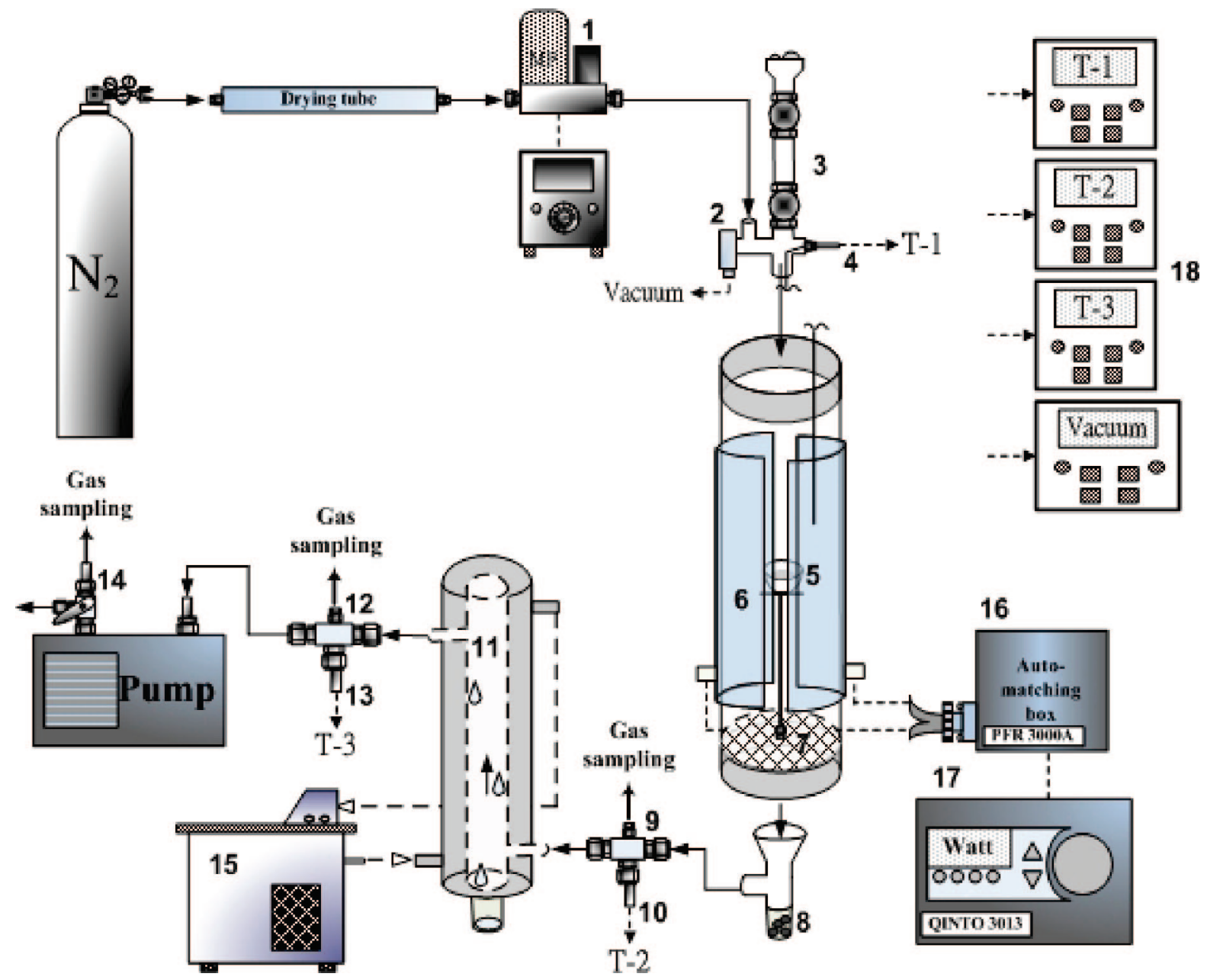

Figure 1. Schematic diagram of the RF plasma thermolysis system: (1) mass flow rate controller; (2) vacuum meter; (3) continuous feeding apparatus; (4, 10, and 13) thermocouples; (5) crucible and its support; (6) copper electrodes; (7) stainless steel net (25 mesh and $0.71 \mathrm{~mm}$ ); (8) solid product storage; (9,12, and 14) gas product samplers; (11) condenser and liquid product collector; (15) circulating thermostat; (16) automatching box; (17) RF plasma power supply; (18) digital monitors.

(Huettinger, QINTO 3013, Germany) and automatching box (Huettinger, PFM3000A, Germany) can provide a maximum voltage of $2000 \mathrm{~W}$ and RF frequency of $13.56 \mathrm{MHz}$. The temperatures are controlled from 300 to $950 \mathrm{~K}$ with the input power of 137 to 591 $\mathrm{W}$ under the net pressure of 1 torr. In this study, the RF plasma thermolysis reactor is used for pyrolyzing the biomass waste of rice straw. The reactor used can be adjusted for batch or continuous operation. In the batch experiment, the sample of rice straw was put in the crucible, which was supported by the stainless steel net. After the completion of experiment, the residual solid product in the crucible was weighted. Three replicates were performed.

The thermogravimetric system (Shimadzu TGA-51) used for the kinetic studies is shown schematically in Figure 2 and is the same as that used in the previous study. ${ }^{32-37}$ It mainly consists of electrobalance and furnace units. Some specifications of the balance mechanism are the following: balance type of taut band, capacity of $10 \mathrm{~g}$, resolution of $1 \mu \mathrm{g}$, accuracy of $1 \%$ of each measuring range. The furnace unit has an electrically heated reaction tube of

(32) Moustakas, K.; Fatta, D.; Malamis, S.; Haralambous, K.; Loizidou, M. J. Hazard. Mater. 2005, B123, 120-126.

(33) Shie, J. L.; Chen, Y. H.; Chang, C. Y.; Lin, J. P.; Lee, D. J.; Wu, C. H. Energy Fuels 2002, 16, 109-118.

(34) Shie, J. L.; Chang, C. Y.; Lin, J. P.; Lee, D. J.; Wu, C. H. J. Chin. Inst. Environ. Eng. 2002, 12, 65-76.

(35) Shie, J. L.; Lin, J. P.; Chang, C. Y.; Lee, D. J.; Wu, C. H. J. Chin. Inst. Environ. Eng. 2002, 12, 363-371.

(36) Wu, C. H.; Chang, C. Y.; Tseng, C. H.; Lin, J. P. J. Chin. Inst. Environ. Eng. 2003, 13, 67-76.

(37) Huang, H. C.; Chang, C. Y.; Chen, Y. H.; Shie, J. L.; Lin, J. P.; Wu, C. H. J. Chin. Inst. Chem. Eng. 2004, 35, 623-632.
$20 \mathrm{~mm}$ in inner diameter and $170 \mathrm{~mm}$ in length. A sample $(6 \pm$ $0.2 \mathrm{mg}$ ) is placed in a Pt cell of $6 \mathrm{~mm}$ in diameter and $2.5 \mathrm{~mm}$ in depth. The cell is then put on a Pt sample pan that is hung by a quartz suspension wire ( $155 \mathrm{~mm}$ long) and connected to the balance mechanism. The temperatures of the furnace reaction tube are in the range $373-1073 \mathrm{~K}$ and controlled by a chromel-alumel thermocouple placed 1-2 mm below the Pt sample pan. The nitrogen gas with a known flow rate (e.g., 50 and $200 \mathrm{~cm}^{3} \mathrm{~min}^{-1}$, $101 \mathrm{kPa}(1 \mathrm{~atm})$, and $293 \mathrm{~K})$ is first introduced into the balance mechanism and then to the furnace reaction tube for at least $2 \mathrm{~h}$ for purging purposes. After $2 \mathrm{~h}$, the furnace unit is set at a specific heating rate (HR; 5 and $75 \mathrm{~K} \mathrm{~min}^{-1}$ ). Meanwhile, the data acquisition unit, with sampling intervals of $1 \mathrm{~s}$, is processing throughout the entire run. The effluent gas is cold-trapped at 298 $\mathrm{K}$ and then collected by a sample bag or vented to a fume hood. When the run is finished, the nitrogen gas is kept flowing until the temperature of the system is below $373 \mathrm{~K}$.

The elemental analyses for the samples were made employing a Perkin-Elmer, Norwalk, CT2400 elemental analyzer with $0.3 \mathrm{wt}$ $\%$ accuracy. The elements of $\mathrm{C}, \mathrm{H}$, and $\mathrm{N}$ were analyzed via Heraeus CHN-O-RAPID, and $\mathrm{S}$ and $\mathrm{Cl}$ analyzed via Tacussel Coulomax 78 automatic coulometric titrator. The heavy metals were measured using inductively coupled plasma atomic emission spectroscopy (ICP/AES; Jarrel-Ash, ICAP 9000). The mass of sample used for the digestion experiment was $0.5 \mathrm{~g}$. For the purposes of analysis, the samples were pretreated by mixing with $2 \mathrm{~mL}$ concentrated $\mathrm{HNO}_{3}, 0.5 \mathrm{~mL} \mathrm{HClO}_{4}$, and $1 \mathrm{~mL} \mathrm{HF}$ and then digested at $443 \mathrm{~K}$ for $6 \mathrm{~h}$. The heating values of samples were measured by the adiabatic bomb calorimeter (O.S.K., 150 vacuum 


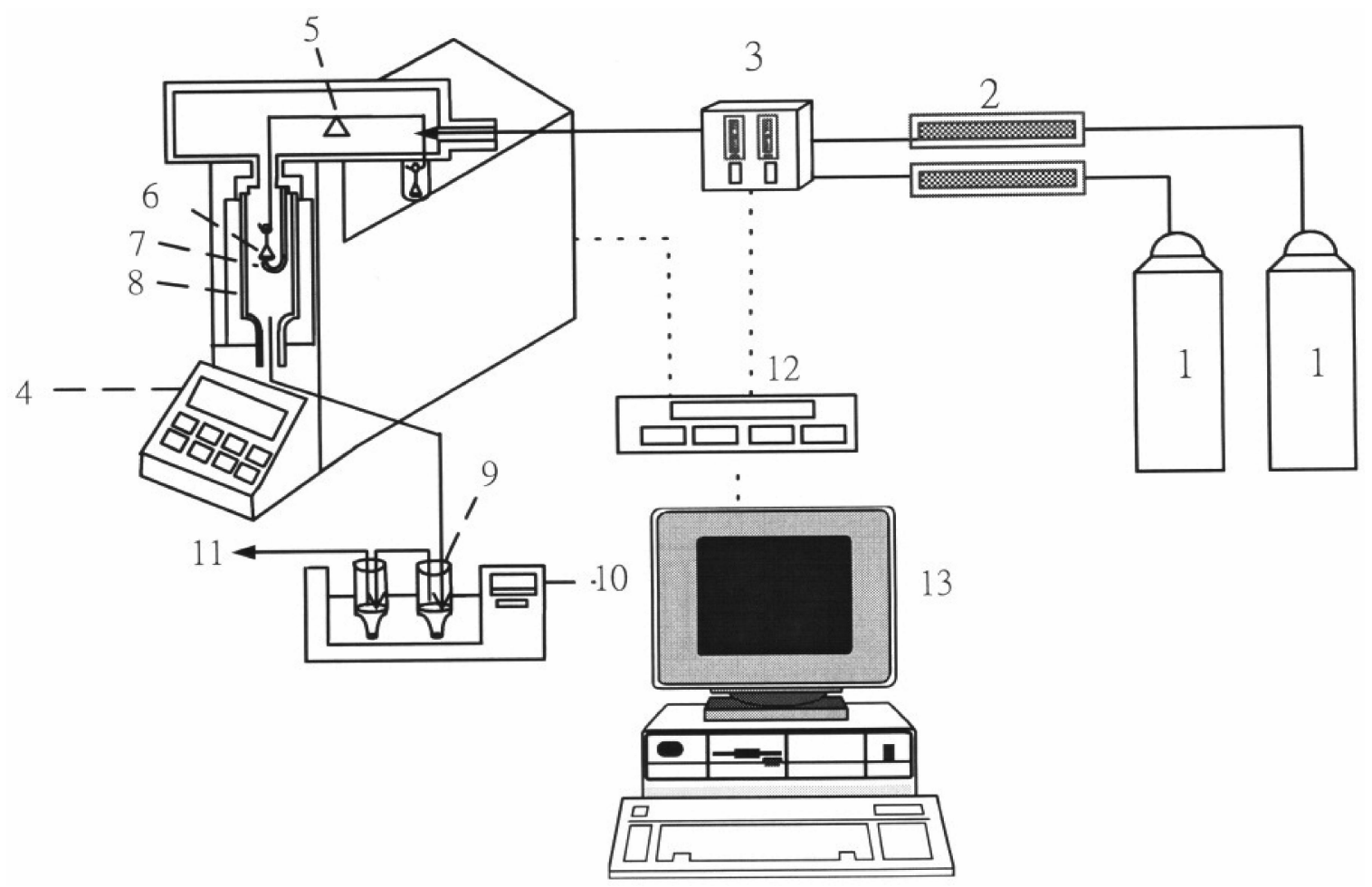

Figure 2. Experimented system of traditional thermolysis system using electric-thermal heating: (1) nitrogen; (2) drying tube; (3) mass flow controller; (4) control board; (5) electrobalance; (6) sample disk; (7) thermocouples; (8) furnace; (9) condenser tubes; (10) constant temperature bath; (11) to sample bag; (12) data acquisition; (13) personal computer. ${ }^{30-35}$

flask oxygen bomb calorimeter). The proximate analysis included moisture, combustible, and ash. The moisture was obtained from the difference between the original mass and the mass after drying for $2 \mathrm{~h}$ at $378 \pm 5 \mathrm{~K}$. The combustible content was measured from the difference between the mass dried for $2 \mathrm{~h}$ at $378 \pm 5$ $\mathrm{K}$ and the final mass burned for $3 \mathrm{~h}$ at $1273 \pm 50 \mathrm{~K}$. The final mass was the ash. The thermogravimetric analyzer (TGA) used in this study is the Shimadzu TGA-51 with $1 \%$ accuracy for recording the variation in mass from 373 to $1123 \mathrm{~K}$.

\section{Results and Discussion}

Pretreatment and Characteristics of the Rice Straw. The biomass used in this study was rice straw. The rice straw sample was exposed under the sunlight for 10 days in order to get rid of the surface water. Then, the sample was broken by spiral breaker and sieved into 30-40 mesh (0.6-0.425 mm) and dried in a recycle ventilation drier for $24 \mathrm{~h}$ at $378 \mathrm{~K}$ before use. The results of proximate, heating value, and elemental analyses of rice straw are listed in Table 1 . The elemental analyses of the metal content of rice straw are presented in Table 2. In Table 1 , the combustible value of rice straw is $79.8 \mathrm{wt} \%$ and the heating value is $4042 \mathrm{kcal} \mathrm{kg}^{-1}$, supporting the use of rice straw as an energy source. The contents of $\mathrm{C}$ and $\mathrm{O}$ of rice straw are 39.6 and $53.7 \mathrm{wt} \%$, respectively. It is obvious that the sulfur, chloride, and nitrogen are rare and can be neglected in the utilization of rice straw. The major mineral matter contents are $\mathrm{Si}, \mathrm{Al}, \mathrm{Na}$, and $\mathrm{Mg}$, and their values are 54803, 1113, 1030, and 990 ppmw, respectively. The total mineral matter is about 59619.6 ppmw. From Table 2, the total value of oxide compounds of mineral matter is about $12.5 \mathrm{wt} \%$ (125074.8 ppmw) and is near with that of ash (11.7 wt \%). The results support that most of the biomasses have similar properties and offer the main advantage of using biomass for energy and
Table 1. Some Properties of Rice Straw Used in This Study

\begin{tabular}{cc}
\hline \multicolumn{1}{c}{ item } & property \\
\hline $\begin{array}{l}\text { proximate analysis (wt \%) } \\
\text { moisture }\end{array}$ & $8.5(0.30)^{a}$ \\
combustible & $79.8(0.90)$ \\
ash & $11.7(1.15)$ \\
heating value of dry basis $\left(\mathrm{kcal} \mathrm{kg}^{-1}\right)$ & 4,042 \\
\hline \multicolumn{3}{c}{ Elemental Analyses (dry basis, wt \%) } \\
\hline $\mathrm{C}$ & $39.6(0.23)$ \\
$\mathrm{H}$ & $5.8(0.32)$ \\
$\mathrm{N}$ & $0.7(0.20)$ \\
$\mathrm{O}$ & $53.7^{b}($ balance) \\
$\mathrm{S}$ & $0.2(0.02)$ \\
$\mathrm{Cl}$ & 0.1
\end{tabular}

${ }^{a}$ Numbers in parentheses are standard deviations $\left(\sigma_{n-1}\right) .{ }^{b}$ Including mineral matter.

resources production from pyrolysis. ${ }^{38}$ The utilization of biomass for energy generation also assists the reduction of $\mathrm{CO}_{2}$ and $\mathrm{SO}_{2}$ emissions for preventing the greenhouse effect and acid rain. ${ }^{39}$

The residual mass fraction $(M)$ of rice straw with respect to the initial mass during pyrolysis by TGA is expressed on a normalized basis as

$$
M=W / W_{0}
$$

where $W$ and $W_{0}$ are the present and initial masses of sample, respectively. The modified residual mass fraction $\left(M_{\mathrm{c}}\right)$ with respect to the combustible mass of sample is defined as

$$
M_{\mathrm{c}}=\left(W-W_{\text {ash }}\right) /\left(W_{0}-W_{\text {ash }}\right)
$$

where $W_{\text {ash }}$ is the mass of ash in the sample. The variation of $M$ with reaction temperature $\left(T_{\mathrm{r}}\right)$ with $\mathrm{HR}$ of $5 \mathrm{~K} \mathrm{~min}^{-1}$ is

(38) Sharma, R. K.; Bakhshi, N. N. Can. J. Chem. Eng. 1991, 69, 10711081.

(39) Liang, X. H; Kozinski, J. A. Fuel 2000, 79, 1477-1486. 
Table 2. Mineral Matter Analysis of Rice Straw (Dry Basis) Used in This Study

\begin{tabular}{|c|c|c|c|c|c|c|c|c|c|c|c|c|}
\hline major metal ppmw ${ }^{a}$ & $\mathrm{Si}$ & $\mathrm{Al}$ & $\mathrm{Na}$ & $\mathrm{Mg}$ & $\mathrm{Ca}$ & $\mathrm{P}$ & $\mathrm{Mn}$ & $\mathrm{Fe}$ & $\mathrm{Zn}$ & $\mathrm{Sr}$ & $\mathrm{Cu}$ & $\mathrm{Ba}$ \\
\hline dry basis & 54803 & 1113 & 1030 & 990.0 & 772.0 & 325.0 & 259.5 & 258.1 & 32.3 & 11.4 & 10.4 & 6.8 \\
\hline oxide compound & $\begin{array}{r}117435 \\
\left(\mathrm{SiO}_{2}\right)\end{array}$ & $\begin{array}{l}2102 \\
\left(\mathrm{Al}_{2} \mathrm{O}_{3}\right)\end{array}$ & $\begin{array}{l}1388 \\
\left(\mathrm{Na}_{2} \mathrm{O}\right)\end{array}$ & $\begin{array}{l}1642 \\
(\mathrm{MgO})\end{array}$ & $\begin{array}{c}1081 \\
(\mathrm{CaO})\end{array}$ & $\begin{array}{l}576.6 \\
\left(\mathrm{P}_{4} \mathrm{O}_{6}\right)\end{array}$ & $\begin{array}{l}410 \\
\left(\mathrm{MnO}_{2}\right)\end{array}$ & $\begin{array}{l}368.7 \\
\quad\left(\mathrm{Fe}_{2} \mathrm{O}_{3}\right)\end{array}$ & $\begin{array}{l}40.2 \\
(\mathrm{ZnO})\end{array}$ & $\begin{array}{l}13.5 \\
(\mathrm{SrO})\end{array}$ & $\begin{array}{l}13.0 \\
\quad(\mathrm{CuO})\end{array}$ & $\begin{array}{l}7.6 \\
\quad(\mathrm{BaO})\end{array}$ \\
\hline major metal $\mathrm{ppmw}^{a}$ & $\mathrm{Cr}$ & & $\mathrm{Ni}$ & $\mathrm{Pb}$ & $\mathrm{Cd}$ & & Cc & As & $\mathrm{Hg}$ & B & $\mathrm{Ag}$ & total \\
\hline dry basis & 4.2 & 3.0 & & 0.6 & 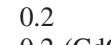 & 0.1 & & ND & ND & ND & ND & 59619.6 \\
\hline oxide compound & $5.5(\mathrm{C}$ & 3.8 & $(\mathrm{NiO})$ & $0.6(\mathrm{PbO})$ & $0.2(\mathrm{Cd}$ & 0.1 & $(\mathrm{CoO})$ & ND & ND & ND & ND & 25074.8 \\
\hline
\end{tabular}

${ }^{a}$ ppmw: ppm in wt/wt.

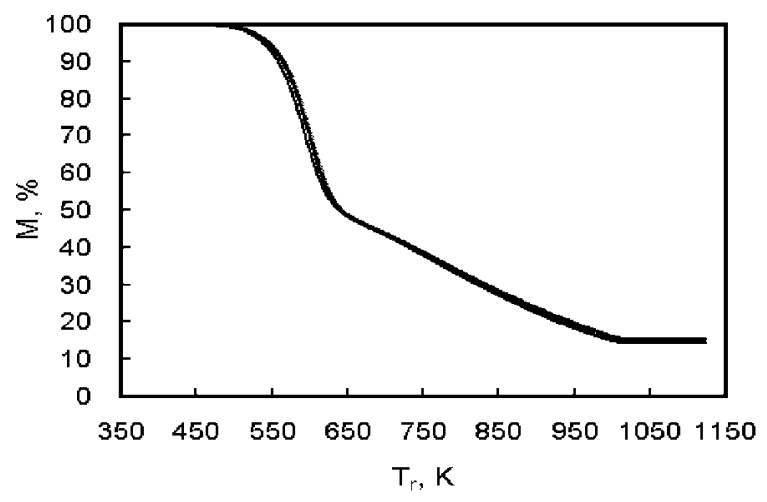

Figure 3. $M$ vs $T_{\mathrm{r}}$ for the pyrolysis of rice straw via TGA: HR $5 \mathrm{~K}$ $\mathrm{min}^{-1} ; W_{0} 6 \pm 0.2 \mathrm{mg} ; d_{\mathrm{P}} 0.425-0.6 \mathrm{~mm}$; carrier gas $\mathrm{N}_{2} ; Q 50 \mathrm{~mL}$ $\min ^{-1} ; M=W / W_{0} ; W, W_{0}$ present and initial masses of sample; $T_{\mathrm{r}}$ reaction temperature; HR heating rate; $d_{\mathrm{P}}$ sample size; $Q$ flow rate of inlet carrier gas; replication 3.

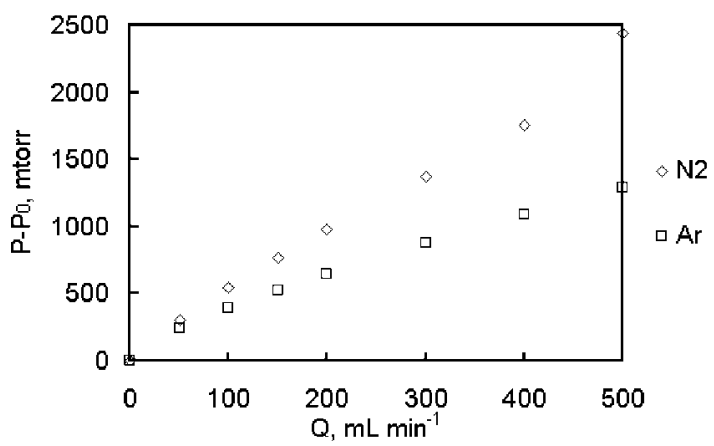

Figure 4. Net pressure $\left(P-P_{0}\right)$ of $\mathrm{N}_{2}(\diamond)$ and $\operatorname{Ar}(\square)$ at various $Q$ values in the RF plasma reactor. $\mathrm{P}$ : Final pressure. $\mathrm{P}_{0}$ : Initial pressure (89 mtorr). Setting of exhaust flow rate of vacuum pump: $40 \mathrm{~L} \mathrm{~min}^{-1}$. $\mathrm{R}^{2}$ for the cases of $\mathrm{N}_{2}$ and Ar: 0.9922 and 0.9843 .

illustrated in Figure 3. The pyrolytic reaction is significant in the range $550-650 \mathrm{~K}$. There are two major reaction steps. The value of $M$ at $1000 \mathrm{~K}$ is about $15 \mathrm{wt} \%$, which is close to the ash content of rice straw $(=11.7 /(79.8+11.7)=14.4$ on a dry basis). Therefore, the plateau temperature $\left(T_{\mathrm{P}}\right)$ for the pyrolysis of rice straw using RF plasma conducted in this study is set at the middle of the second step $(783 \pm 10 \mathrm{~K})$ to ensure an acceptable reaction rate $\left(R_{\mathrm{r}}\right)$ of rice straw.

Operating Procedure and Characteristics of the RF Plasma Thermolysis Reaction. The effects of system parameters on the performance of RF plasma thermolysis of rice straw were examined. These include types of carrier gas, $Q$, net pressure $(P-$ $\left.P_{0}\right)$ in the reactor, loading power $\left(P_{\mathrm{WL}}\right)$, reaction time $(t)$, and $T_{\mathrm{r}}$. $P$ is the final pressure, while $P_{0}$ is the initial pressure under vacuum. $P_{\mathrm{WL}}$ can be online measured and recorded via the RF plasma power supply device. The net pressures $\left(P-P_{0}\right)$ of $\mathrm{N}_{2}$ and $\mathrm{Ar}$ in the RF plasma reactor at various values of $Q$ are shown in Figure 4. For the pyrolysis experiments that followed using RF plasma, $Q$ of $\mathrm{N}_{2}$ or Ar was set at $200 \mathrm{~mL} \mathrm{~min}^{-1}$ and the net pressures of $\mathrm{N}_{2}$ and $\mathrm{Ar}$ (with $P_{0}=89$ mtorr) were $1.00 \pm 0.2$ and $0.66 \pm 0.2$ torr,

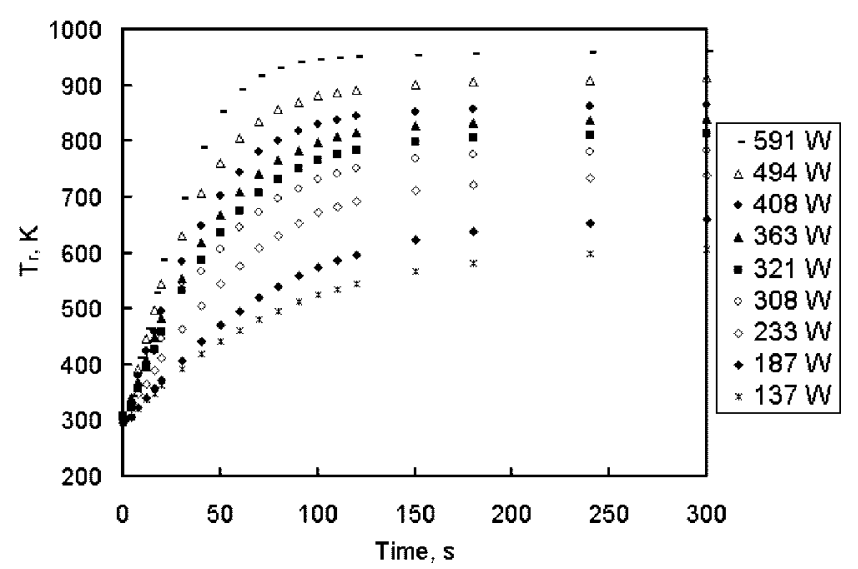

Figure 5. Time variation of $T_{\mathrm{r}}$ at various loading powers $\left(P_{\mathrm{WL}}\right)$ in the RF plasma reactor. $P_{\mathrm{WL}}=P_{\mathrm{WI}}-P_{\mathrm{WR}} ; P_{\mathrm{WI}}, P_{\mathrm{WR}}$ powers supplied and reflected; carrier gas $\mathrm{N}_{2} ; Q 200 \mathrm{~mL} \mathrm{~min}^{-1}$; net pressure $1.00 \pm 0.2$ torr; initial or room temperature $\left(T_{0}\right) 298 \pm 5 \mathrm{~K}$.

respectively. The low values of the net pressures ensure gas flowing through the plasma thermolysis system with no leakage problem in experiments.

For temperature control, the time variations of $T_{\mathrm{r}}$ at various $P_{\mathrm{WL}}$ are shown in Figure 5. $P_{\mathrm{WL}}$ is the loading power used for the generation of RF plasma. It is equal to the input power $\left(P_{\mathrm{WI}}\right)$ minus reflected power $\left(P_{\mathrm{WR}}\right) . P_{\mathrm{WI}}$ is the power supplied from the RF plasma power supply, and $P_{\mathrm{WR}}$ is the useless power producing the wasted electromagnetic wave from reflection. Figure 6 shows $P_{\mathrm{WL}}$ vs $T_{\mathrm{p}}$ and HR in the RF plasma reactor. The values of HR and $T_{\mathrm{P}}$ are directly related to $P_{\mathrm{WL}}$ with a higher $P_{\mathrm{WL}}$ giving higher $\mathrm{HR}$ and $T_{\mathrm{P}}$ values. Obviously, HR can reach about $400 \mathrm{~K} \mathrm{~min}^{-1}$ at a $P_{\mathrm{WL}}$ of $600 \mathrm{~W}$. According to Figure 5, the characteristics of the RF plasma thermolysis reactor with the working gas $\mathrm{N}_{2}$ indicate that as $P_{\mathrm{WL}}$ increases from 137 to $591 \mathrm{~W}$, the $T_{\mathrm{P}}$ of plasma increases from 607 to $954 \mathrm{~K}$. The corresponding $T_{\mathrm{P}}$ at various values of $P_{\mathrm{WL}}$ are $607 \mathrm{~K}$ at $137 \mathrm{~W}, 661 \mathrm{~K}$ at $187 \mathrm{~W}, 738 \mathrm{~K}$ at $233 \mathrm{~W}, 784 \mathrm{~K}$ at $308 \mathrm{~W}$, $810 \mathrm{~K}$ at $321 \mathrm{~W}, 833 \mathrm{~K}$ at $363 \mathrm{~W}, 853 \mathrm{~K}$ at $408 \mathrm{~W}, 901 \mathrm{~K}$ at $494 \mathrm{~W}$, and $954 \mathrm{~K}$ at $591 \mathrm{~W}$, respectively. The corresponding $t_{\mathrm{HP}}$ values to reach $T_{\mathrm{P}}$ values of 607 and $954 \mathrm{~K}$ are about 5 and 2 min, respectively. Thus, a higher $P_{\mathrm{WL}}$ gives a higher $T_{\mathrm{P}}$ with a shorter $t_{\mathrm{HP}}$. The values of heating times $t_{\mathrm{HS}}$ with $P_{\mathrm{WL}}$ values of 308,363 , and $591 \mathrm{~W}$ to reach a setting temperature $T_{\mathrm{S}}$ at $783 \mathrm{~K}$ are about 5, 1.5, and $0.67 \mathrm{~min}$, respectively. Again, a higher $P_{\mathrm{WL}}$ needs a shorter $t_{\mathrm{HS}}$ to reach the same $T_{\mathrm{S}}$.

Comparison of Performances of Thermolysis Using RF Plasma and Traditional Methods. The performances of RF plasma thermolysis and traditional thermolysis of rice straw were compared. For comparison, the initial weight $W_{0}$ and sample size $\left(d_{\mathrm{P}}\right)$ of rice straw, $Q$ of $\mathrm{N}_{2}$, and $T_{\mathrm{P}}$ were controlled at the same conditions for the two thermolysis methods with $W_{0}$ of $100 \pm 10 \mathrm{mg}, d_{\mathrm{P}}$ of $30-40$ mesh (0.6-0.425 mm), $Q$ of 200 $\mathrm{mL} \mathrm{min}^{-1}$ of $\mathrm{N}_{2}$, and $T_{\mathrm{P}}$ of $783 \pm 10 \mathrm{~K}$, respectively. The major difference between these two cases is their heating methods. 

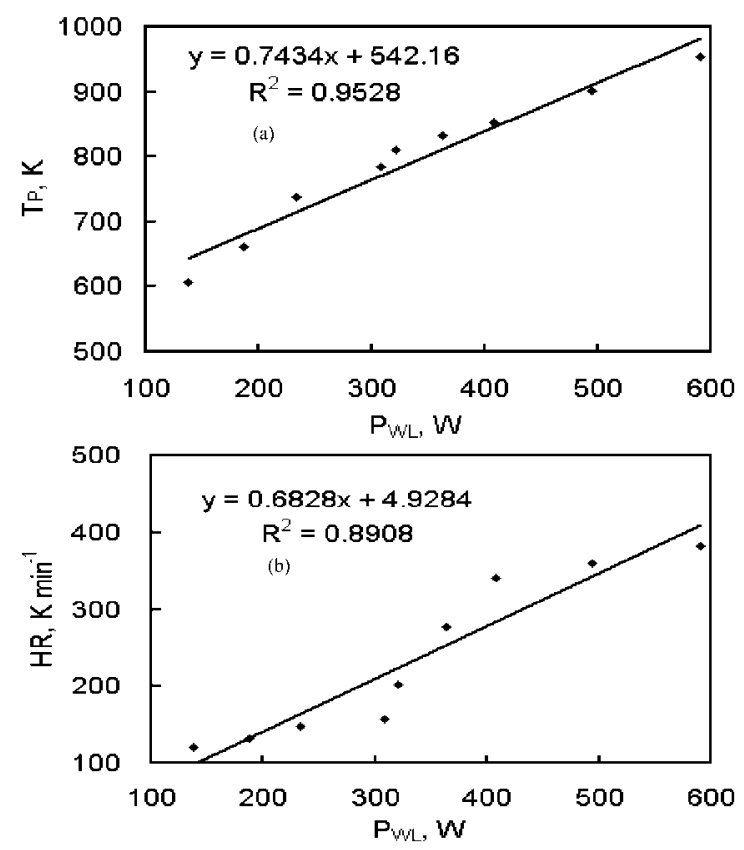

Figure 6. Loading power $\left(P_{\mathrm{WL}}\right)$ vs plateau temperature $\left(T_{\mathrm{p}}\right)$ and heating rate (HR) in the RF plasma reactor. $P_{\mathrm{WL}}=P_{\mathrm{WI}}-P_{\mathrm{WR}} ; P_{\mathrm{WI}}, P_{\mathrm{WR}}$ powers supplied and reflected; carrier gas $\mathrm{N}_{2} ; Q 200 \mathrm{~mL} \mathrm{~min}^{-1}$; net pressure $1.00 \pm 0.2$ torr; initial or room temperature $\left(T_{0}\right) 298 \pm 5 \mathrm{~K}$. (a) $P_{\mathrm{WL}}$ vs $T_{\mathrm{p}}$. (b) $P_{\mathrm{WL}}$ vs HR.

The RF plasma reactor produces plasma with ionization gas to heat the rice straw while the traditional furnace uses electric-thermal energy for heating the rice straw. The operating parameter of $P_{\mathrm{WL}}$ for reaching $T_{\mathrm{P}}$ of $783 \mathrm{~K}$ in the RF plasma reactor is $308 \pm 4 \mathrm{~W}$. For the comparison, the HR of a traditional furnace is set at the highest limited value of 70-75 $\mathrm{K} \min ^{-1}$ for reaching a $T_{\mathrm{P}}$ of $783 \mathrm{~K}$. Under the highest HR of the traditional heating method, the input power is near 1000 $\mathrm{W}$. Therefore, the input power of RF plasma is lower than that of TGA in this study. The conditions of the traditional heating method are near the RF plasma reactor, such as plateau temperature $\left(T_{\mathrm{p}}\right) 783 \pm 10 \mathrm{~K}$, initial mass of sample $\left(W_{0}\right) 100$ $\pm 10 \mathrm{mg}$, sample size $\left(d_{\mathrm{P}}\right) 0.425-0.6 \mathrm{~mm}$, carrier gas $(Q)$ of $\mathrm{N}_{2}: 200 \mathrm{~mL} \mathrm{~min}^{-1}$, initial or room temperature $\left(T_{0}\right) 298 \pm 5$ $\mathrm{K}$. The only different condition is the heating rate $\left(95 \mathrm{~K} \mathrm{~min}^{-1}\right.$ of RF plasma and $70-75 \mathrm{~K} \mathrm{~min}^{-1}$ of the traditional heating method). This is because of the power limited of traditional heating method with maximum power of $1000 \mathrm{~W}$ at highest heating rate of $70-75 \mathrm{~K} \mathrm{~min}^{-1}$.

From Figures 7 and 8 , the values of $t_{\mathrm{HP}}$ of RF plasma thermolysis and traditional thermolysis are 5 and 6-7 min, respectively. At the reaction time of $90 \mathrm{~min}$, the values of $M_{\mathrm{c}}$ of rice straw for the pyrolyses with RF plasma and traditional methods are about 50 and $42.6 \mathrm{wt} \%$, respectively. The corresponding thermolysis efficiencies of the RF plasma and TGA methods are 50 and 57.4 wt \%, respectively. Note that the HRs of pyrolyses for the RF plasma and traditional methods are 95 and $70-75 \mathrm{~K} \mathrm{~min}^{-1}$, respectively. When we focus on $M_{\mathrm{c}}$ at $90 \mathrm{~min}$, the thermolysis efficiency of traditional thermolysis method (57.4\%) is slightly higher than that of the RF plasma thermolysis method (50\%). However, if we note $M_{\mathrm{c}}$ and the corresponding $T_{\mathrm{r}}$ at the same time scale, we can find something interesting. In the RF plasma thermolysis system, $M_{\mathrm{c}}$ decreases about 3\% only as $T_{\mathrm{r}}$ increases from $T_{0}$ to $T_{\mathrm{P}}$ while it retains 97\% for further thermolysis at $T_{\mathrm{P}}$ counting for a decomposition of rice straw of $47 \%$ ( $=50 \%-3 \%$ ). The $R_{\mathrm{r}}$ of an RF plasma thermolysis system is about $0.55 \mathrm{wt} \% \min ^{-1}$ at $T_{\mathrm{p}}$. As for the
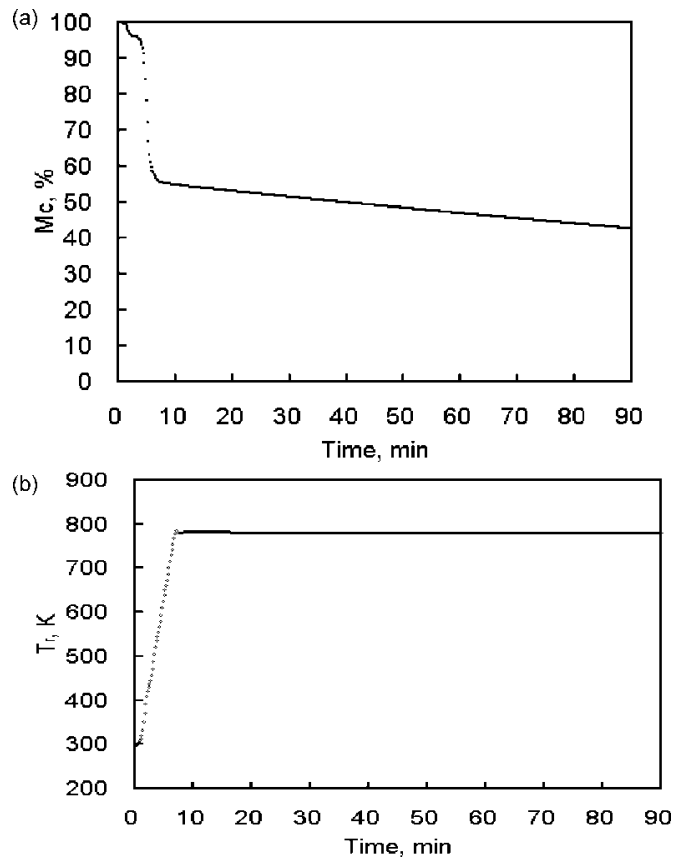

Figure 7. Time variations of $M_{\mathrm{c}}$ and $T_{\mathrm{r}}$ for the pyrolysis of rice straw via the traditional heating method at $T_{\mathrm{P}}=783 \mathrm{~K}$ : HR $70-75 \mathrm{~K} \mathrm{~min}^{-1} ; T_{\mathrm{P}} 783$ $\pm 10 \mathrm{~K} ; W_{0} 100 \pm 10 \mathrm{mg} ; d_{\mathrm{P}} 0.425-0.6 \mathrm{~mm}$; carrier gas $\mathrm{N}_{2} ; Q 200 \mathrm{~mL}$ $\min ^{-1} ; T_{0} 298 \pm 5 \mathrm{~K}$; replication 4. (a) $M_{\mathrm{c}}$ vs time. (b) $T_{\mathrm{r}}$ vs time.

Table 3. Fractions ${ }^{a}$ of the Products of Combustible Solid Remained, Liquid, and Gas from the Thermolysis of Rice Straw Using RF Plasma and Traditional Methods at $T_{\mathrm{P}}=783 \mathrm{~K}$ with a Reaction Time of $90 \mathrm{~min}$

\begin{tabular}{llcc}
\hline & $\begin{array}{c}\text { combustible solid } \\
\text { remained } \\
\text { thermolysis/product }\end{array}$ & $\begin{array}{c}\text { liquid } \\
\text { products } \\
\left(M_{\mathrm{c}} \text {; wt \%) }\right.\end{array}$ & $\begin{array}{c}\text { gas } \\
\text { product } \\
(\text { wt \%) }\end{array}$ \\
\hline RF plasma thermolysis & 50.0 & 0 & 50.0 \\
traditional thermolysis & 42.6 & 1.5 & 55.9 \\
Tang and Huang & $34(11.6-67.5)^{b}$ & & 66
\end{tabular}

${ }^{a}$ Ash free basis, i.e., with respect to the initial mass of sample excluding ash $\left(W_{0}-W_{\text {ash }}\right){ }^{b}$ Range for different operating conditions.

traditional thermolysis system, $M_{\mathrm{c}}$ decreases from the initial value $\left(M_{\mathrm{c} 0}\right)$ of 1 to 0.56 as $T_{\mathrm{r}}$ increases from $T_{0}$ to $T_{\mathrm{P}}$ in the heating stage, yielding a decomposition of $44 \%(=(1-0.56) /$ 1) with respect to $M_{\mathrm{c} 0}$. For further thermolysis at constant $T_{\mathrm{p}}$, $M_{\mathrm{c}}$ reduces to 0.426 at 90 min giving an overall decomposition of $57.4 \%(=(1-0.426) / 1)$ with respect to $M_{\mathrm{c} 0}$. Thus, the incremental net contribution of decomposition during thermolysis at constant $T_{\mathrm{p}}$ is only $13.4 \%$ (=57.4\% $\left.-44 \%\right)$. Therefore, the $R_{\mathrm{r}}$ of a traditional thermolysis system is $0.16 \mathrm{wt} \% \mathrm{~min}^{-1}$ at $T_{\mathrm{p}}$. Comparison at $T_{\mathrm{p}}$, the $R_{\mathrm{r}}$ of the RF plasma thermolysis system is 3.44 times higher than that of a traditional thermolysis system. The enhancement effect on $R_{\mathrm{r}}$ of an RF plasma thermolysis system is very obvious. Higher $R_{\mathrm{r}}$ will decrease reaction time and energy demand.

Further, for a fair comparison of the two methods, we also have to note the tar content in the gas produced from the pyrolysis of biomass, which always plays an important role for the operation of the thermolysis process. A high tar content may cause the corroding problem of the device and increase the need for the further treatment of the gas produced. Although the composition of syngas in the gas product is not available, however, plasma technologies for the thermolysis of biomass would not only yield high concentrations of syngas but also result in low concentrations of tar in a gas phase, mostly below $10 \mathrm{mg} \mathrm{Nm}^{-3}$ as noted by Hlina et al. ${ }^{40}$ 

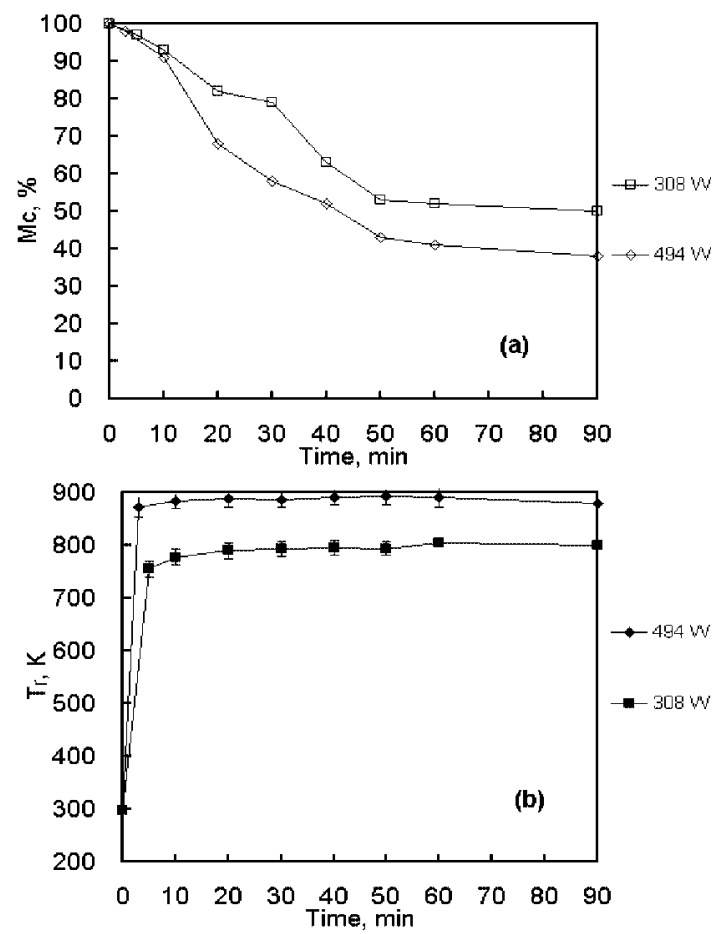

Figure 8. Time variations of $M_{\mathrm{c}}$ and $T_{\mathrm{r}}$ for the pyrolysis of rice straw via $\mathrm{RF}$ plasma method at $T_{\mathrm{P}}=783$ and $883 \mathrm{~K}$ with $P_{\mathrm{WL}}=308 \pm 4$ and $494 \pm 4 \mathrm{~W}$, respectively: HR 95 and $190 \mathrm{~K} \mathrm{~min}^{-1} ; T_{\mathrm{P}} 783 \pm 10$ and $883 \pm 10 \mathrm{~K} ; W_{0} 100 \pm 10 \mathrm{mg} ; d_{\mathrm{P}} 0.425-0.6 \mathrm{~mm}$; carrier gas $\mathrm{N}_{2}$; $Q: 200 \mathrm{~mL} \mathrm{~min}{ }^{-1}$. $\mathrm{P}-\mathrm{P}_{0}: 1.00 \pm 0.2$ torr. $\mathrm{T}_{0}: 298 \pm 5 \mathrm{~K}$. (a) Mc vs. time, (b) $T_{r}$ vs. time.

Fractions of Products of Combustible Solid Remained, Liquid, and Gas. Table 3 lists the fractions of the products of combustible solid remained $\left(M_{\mathrm{c}}\right)$, liquid, and gas from the thermolysis via RF plasma and traditional methods which clearly indicates the differences between these two heating methods. The values are expressed on an ash free basis with respect to the initial mass of sample excluding ash $\left(W_{0}-W_{\text {ash }}\right)$. Noting that the sample of rice straw was dried before use, we can conclude that the liquid products are the tar and some complex compounds of high boiling point. ${ }^{2}$ Pütün et al. ${ }^{41}$ studied the pyrolysis of rice straw to estimate the effect of pyrolysis conditions on product yields and bio-oil composition. The subfractions of bio-oil from pyrolysis of rice straw are $27.48 \mathrm{wt} \%$ aliphatic, $11.46 \mathrm{wt} \%$ aromatic, $31.28 \mathrm{wt} \%$ ester, and $29.78 \mathrm{wt} \%$ polar. From the gas-liquid chromatogram of the $n$-pentane, i.e. aliphatic subfraction for bio-oil, the straight chain alkanes and alkenes range between $\mathrm{C}_{9}-\mathrm{C}_{28}$ and the distribution of straight chain alkanes exhibits a maximum on the range of $\mathrm{C}_{10}-\mathrm{C}_{14}$. Tang and Huang ${ }^{42}$ used a laboratory-scale capacitive coupled radiofrequency (RF) plasma pyrolysis reactor to examine the characteristics of this RF plasma reactor and the products of fir sawdust gasification. It was founded that sawdust gasification using an input power of $1600-2000 \mathrm{~W}$ and a reactor pressure of $3000-8000 \mathrm{~Pa}$ produced gas consisting of $\mathrm{H}_{2}(3.88-11.06 \mathrm{vol} \%), \mathrm{CO}(5.21-14.82$ vol \%), $\mathrm{CH}_{4}\left(1.38-2.48\right.$ vol \%), $\mathrm{CO}_{2}\left(1.51-5.05\right.$ vol \%), and $\mathrm{C}_{2}$ $(1.5-3.92 \mathrm{vol} \%)$ as well as char. On average, the gas yield can reach $66 \mathrm{wt} \%$ of the sawdust feed, and the comparison with this study is listed in Table 3.

About 1.5 wt \% liquid products were collected from the thermolysis using the traditional method. These products exist in the form of tar with very high viscosity and deposits on the

(40) Hlina, M.; Hrabovsky, M.; Kopecky, V.; Konrad, M.; Kavka, T.; Skoblja, S. Czech. J. Phys. 2006, 56, B1179-B1184.

(41) Pütün, A. E.; Apaydm, E.; Pütün, E. Energy 2004, 29, 2171-2180.

(42) Tang, L.; Huang, H. Fuel 2005, 84, 2055-2063. inner wall of condenser tubes. On the other hand, no liquid products were collected from the RF plasma thermolysis in this study. This may be contributed to the causes that only a small amount of rice straw (nearly 3\%) was decomposed in the heating stage with temperature rise and that the energy species generated via RF plasma can enhance the decomposition of tar and complex compounds if they were produced.

From these findings, it is believed that the gaseous product obtained via thermolysis using RF plasma contains more hydrocarbons of low molecular weight than those using traditional electric-thermal heating. A further study on the characteristics of gas product would be helpful for supporting the above points.

Thermolysis via RF Plasma at Various Plateau Temperatures. Figure 8 shows the results of thermolysis of rice straw via RF plasma performed at two different heating conditions with $T_{\mathrm{P}}$ at 783 and $883 \mathrm{~K}$, corresponding to $P_{\mathrm{WL}}$ values of $308 \pm$ 4 and $494 \pm 4 \mathrm{~W}$, respectively. With $P_{\mathrm{WL}}$ values of 308 and 494 $\mathrm{W}$, the RF plasma took about 5 and $3 \mathrm{~min}$ to raise the thermolysis temperature $T_{\mathrm{r}}$ from $T_{0}$ to 783 and $883 \mathrm{~K}$ with weight losses of rice straw of $3 \%$ and $2 \%$ in terms of $M_{\mathrm{c}}$, respectively. Besides, at a reaction time of $90 \mathrm{~min}$, the case with a $P_{\mathrm{WL}}$ of $494 \mathrm{~W}$ offered better decomposition than that of $308 \mathrm{~W}$, with the decomposition efficiencies of $62 \%$ and $50 \%$, respectively. Thus, a higher $P_{\mathrm{WL}}$ needs less time to raise $T_{\mathrm{r}}$ from $T_{0}$ to $T_{\mathrm{P}}$ and gives a better thermolysis efficiency.

\section{Conclusions}

1. RF plasma thermolysis offers a faster heating rate and can retain more residues of rice straw than the traditional thermolysis via electric-thermal heating at the same plateau temperature $T_{\mathrm{P}}$.

2. RF plasma thermolysis has no corroding problem because no tar is formed, while traditional pyrolysis results in about 1.5 wt $\%$ of tar for the experimental conditions examined in this study.

3. The time for the RF plasma process to reach $T_{\mathrm{P}}$ is short, decreasing the formation of complex compounds from intermediate residues at various temperatures during the period of temperature rise. We can infer that the contents of gas products from the RF plasma thermolysis of rice straw are simpler with better quality than those from traditional thermolysis.

Acknowledgment. We express our sincere thanks to the National Science Council of Taiwan for the financial support, under the contract number NSC94-2218-E-002-070.

\footnotetext{
$d_{\mathrm{P}}=$ sample size, $\mathrm{mm}$

$\mathrm{HR}=$ heating rate, $\mathrm{K} \mathrm{\textrm {min } ^ { - 1 }}$

$M=$ residual mass fraction, -

$M_{\mathrm{c}}=$ modified residual mass fraction, -

$P=$ final pressure, torr

$P_{0}=$ initial pressure, torr

$P_{\mathrm{WI}}=$ input power, $\mathrm{W}$

$P_{\mathrm{WL}}=$ loading power, $\mathrm{W}$

$P_{\mathrm{WR}}=$ reflected power, $\mathrm{W}$

$Q=$ flowrate of carrier gas, $\mathrm{mL} \mathrm{min}^{-1}$

$R_{\mathrm{r}}=$ reaction rate, $\mathrm{wt} \% \mathrm{~min}^{-1}$

$T_{0}=$ initial or room temperature, $\mathrm{K}$

$T_{\mathrm{P}}=$ plateau temperature, $\mathrm{K}$

$T_{\mathrm{S}}=$ setting temperature, $\mathrm{K}$

$T_{\mathrm{r}}=$ reaction temperature, $\mathrm{K}$

$t_{\mathrm{H}}=$ heating time, $\min$

$t_{\mathrm{HP}}=$ value of $t_{\mathrm{H}}$ to reach $T_{\mathrm{P}}$, min

$t_{\mathrm{HS}}=$ value of $t_{\mathrm{H}}$ to reach $T_{\mathrm{S}}$, min

$W=$ present mass of sample, $\mathrm{mg}$

$W_{0}=$ initial mass of sample, $\mathrm{mg}$

$W_{\text {ash }}=$ mass of ash in sample, $\mathrm{mg}$
}

EF7002848 